
перспективы исследований керамики как исторического источника // Керамика как исторический источник (подходы и методы изучения). Тез. докл. Всесоюз. науч. археологич. конф. Куйбышев, 1991. С. 4-7.

18. Цетлин Ю.Б. Неолит центра Русской равнины: орнаментация керамики и методика периодизации культур. Тула: Гриф и К. 2008. 352 с.

19. Цетлин Ю.Б. Фундаментальные проблемы изучения гончарства // Древнее гончарство: итоги и перспективы изучения. М.: ИА РАН, 2010. С. 229-244.

20. Цетлин Ю.Б. Об определении степени ожелезненности исходного сырья для производства глиняной посуды // Вопросы археологии Поволжья: Вып. 4. Самара: Изд-во «Научно-технический центр», 2006. C. 421-425.

\title{
TECHNOLOGICAL ANALYSIS OF ENEOLITHIC CERAMICS OF THE SETTLEMENT NOVOILYINKA III
}

(C) 2015

\author{
S.Z. Rakhimzhanova, post-graduate student \\ Altai State University, Barnaul (Russia)
}

\begin{abstract}
In the article is expounded the first results of the special technological research of eneolithic ceramics from excavation of the settlement of Novoilyinka III from Northern Kulunda that is dated by the first half of the III millennium BC. The research of ceramics is conducted within historical and cultural approach by A.A. Bobrinsky's technique by the steps of potter's technology relating to a preparatory stage of production.

The author recorded an existing on Novoilyinka III'S settlement of carriers of different potter's traditions in skills of selection and preparation of initial raw materials and drawing up forming mass of ceramics. The most peculiar feature of Noboilynka's III ceramics is an addition of a big quantity of fluff to the moldind mass. The similar cultural tradition in Southern Siberia isn't revealed yet. As a result of the analysis were revealed 9 different «places» of mining of initial raw materials. There were allocated 4 different cultural traditions of drawing up forming mass of ceramics. Among the 4 allocated recipes of forming masses the most mass - «clay + fluff + organic» $(75,1 \%)$ that talks about a high degree of uniformity of carriers of potter's traditions. There was a case where «clay + chamotte + gruss + organic» were used by potters and that reflects the mixture of cultural traditions in the field of drawing up forming masses

Keywords: eneolith; the settlement of Novoilyinka III; Northern Kulunda; ceramics; historical and cultural approach; the technological analysis; potter's traditions.
\end{abstract}

УДК 902
КУЛЬТУРНЫЕ ТРАДИЦИИ В ВЫБОРЕ ИСХОДНОГО СЫРЬЯ И МИНЕРАЛЬНЫХ ПРИМЕСЕЙ ПРИ ИЗГОТОВЛЕНИИ КЕРАМИКИ ПО МАТЕРИАЛАМ ГОРНЫХ, ПРЕДГОРНЫХ, СТЕПНЫХ И ЛЕСОСТЕПНЫХ РАЙОНОВ АЛТАЯ

(C) 2015

\author{
Н.Ф. Степанова, кандидат исторических наук \\ Институт археологии и этнографии СО РАН, \\ Лаборатория археологии и этнографии Южной Сибири, Барнаул (Россия)
}

\footnotetext{
Аннотащия. Статья посвящена обобщению результатов технико-технологического анализа керамики из поселенческих и погребальных комплексов Алтая, датируемой от эпохи неолита до средневековья. Анализируются культурные традиции отбора исходного сырья и подготовки формовочных масс древнего населения региона в зависимости от ландшафтных характеристик районов расположения памятников. Установлено, что для степных, лесостепных и предгорных районов было характерно использование ожелезненных пластичных глин, а для горных - низко- и среднеожелезненного глиноподобного сырья. Выявлены различия культурных традиций и в использовании минеральных примесей, совпадающие с ландшафтными характеристиками районов. Добавление шамота характерно для лесостепного и степного Алтая (69\% и 65\%), а дресвы для предгорного (69\%). В Горном Алтае основной традицией было изготовление керамики без искусственно введенных минеральных примесей: шамот и дресва зафиксированы соответственно в $13 \%$ и $17 \%$ сосудов, что в общей сложности составляет 30\%. Смешанные рецепты (дресва + шамот) наиболее распространены в периферийных районах предгорной зоны. Подобные наблюдения позволили сделать вывод, что в районах, где имеются выходы камня, в формовочные массы добавляли дресву, а шамот - в местах, где камня не было. Смешанные рецепты (дресва + шамот) отражают не только смешение культурных традиций, но и населения из разных ландшафтных районов.

Ключевые слова: керамика, исходное сырье, минеральные примеси, шамот, формовочные массы, культурные традиции, ландшафт, неолит, афанасьевская и большемысская культура, эпоха бронзы, ранний железный век, Алтай.
} 
Керамика - один из важнейших источников информации о древнем населении, который до сих пор используется лишь частично. Исследования керамических комплексов с территории Южной Сибири по методике А.А. Бобринского в рамках историко-культурного подхода $[1 ; 2 ; 3 ; 4 ; 5]$ ограничиваются, в основном, административными границами республики Алтай и Алтайского края и в меньшей степени сопредельными территориями $[6 ; 7 ; 8 ; 9$; 10; 11 и др.]. Указанные территории объединяют горные, предгорные, степные и лесостепные районы (рис. 1). Исследуемая керамика датируется периодом от неолита до средневековья (V-IV тыс. до н.э. - сер. I тыс. н.э.). Ареал некоторых культур и типов памятников локализован территориями с одинаковым ландшафтом, другие распространены как в горных, так и лесостепных районах. Например, памятники афанасьевской культуры найдены в горной местности, большемысской культуры, ирбинского, крохалевского типов - в горной, предгорной зонах и на равнинной территории Алтая [12; 13 и др.].

В результате технико-технологического анализа были выявлены культурные традиции отбора исходного сырья и подготовки формовочных масс, свойственные населению следующих археологических культур: среднекатунской, афанасьевской, большемысской, староалейской, ирбинского и крохалевского типа памятников и др. $[10 ; 11 ; 14]$. Получены данные, которые подтверждают наличие общих традиций и навыков изготовления керамики у населения эпохи неолита и бронзы Горного Алтая, но фиксируют отсутствие их преемственности у населения эпохи неолита и афанасьевской культуры - с одной стороны, и афанасьевской культуры и эпохи бронзы - с другой. Этот вывод в совокупности с другими данными указывает на неместный характер афанасьевского населения в Горном Алтае [9; 15].

Продолжение исследований в рамках историкокультурного подхода, анализ результатов изучения исходного сырья и состава формовочных масс выявили навыки изготовления керамики не только для отдельных археологических культур, но и подтвердили наблюдения, сделанные ранее, в частности, о зависимости культурных традиций в выборе минеральных примесей от ландшафтных особенностей районов расположения памятников.

Основной задачей исследования было выявление специфики культурных традиций на двух ступенях производственного процесса (отбор исходного сырья и подготовка формовочных масс). В рамках этой задачи рассматривались вопросы: 1) выделение культурных традиций отбора исходного сырья и подготовки формовочных масс; 2) определение местного и неместного характера культурных традиций отбора сырья и подготовки формовочных масс; 3) выявление признаков смешения этих традиций. С помощью бинокулярного микроскопа МБС-10 изучались свежие изломы и поверхности образцов. При изучении особенностей исходного сырья устанавливалась степень ожелезненности глин, характер содержащихся в них грубых примесей, случаи использования одной или двух глин. Для определения степени ожелезненности глин образцы дополнительно нагревались в окислительной среде в муфельной печи при температуре $850^{\circ} \mathrm{C}$. В общей сложности исследовано свыше 2000 образцов.

\section{Горный Алтай}

Территориальные границы совпадают с административными границами Республики Алтай. Исследована керамика эпохи неолита, бронзы, раннего железного века (среднекатунской, афанасьевской, большемысской культур, ирбинского, крохалевского, куротинского и елунинского типов) из погребальных и поселенческих комплексов.

Исходное сырье. Прослеживаются две традиции в его использовании: 1) низко- и среднепластичное глиноподобное сырье, в котором соотношение глины и естественных минеральных примесей достигало 1:1, а частицы могли иметь размеры до $0,1 \times 0,7 \times 1,0$ см, $0,1 \times 1,0 \times 1,5$ см и более (рис. $2 ; 3$ ); и 2) пластичные глины. В глиноподобном сырье встречаются и кварцевые частицы, и полуразложившиеся минералы, некоторые внешне напоминают плотные вытянутые комочки глины. Их отличия от глины нередко выявляются при механическом воздействии на них и видны в свежих сколах. Возможно, выбор сырья мог быть обусловлен как большей доступностью низко- и среднепластичного сырья, так и его свойствами, т.е. не требовалось вводить искусственные минеральные примеси, а сосуды из него соответствовали предъявляемым требованиям.

Эти две традиции отбора исходного сырья выявлены уже с эпохи неолита, зафиксированы по большемысской керамике, а также сосудах эпохи бронзы и раннего железного века. Для раннего железного века отмечается различие в отборе сырья для керамики погребальных комплексов (низко- и среднепластичное) и поселенческих (пластичное). Выделяется керамика

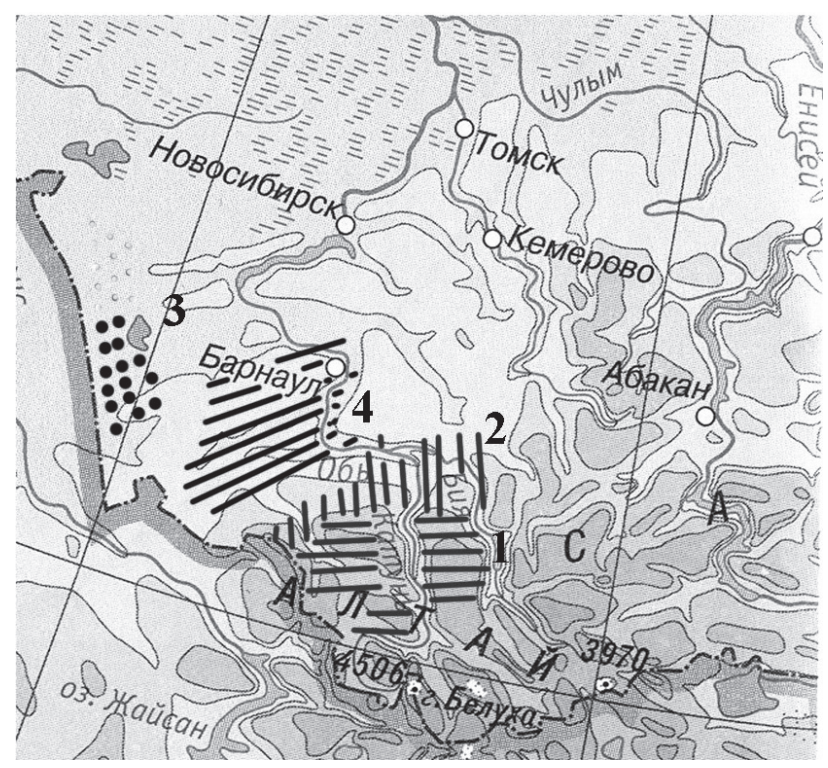

Рисунок 1 - Карта-схема районов с изученной керамикой: 1 - горные, 2 - предгорные, 3 - степные, 4 - лесостепные районы. 


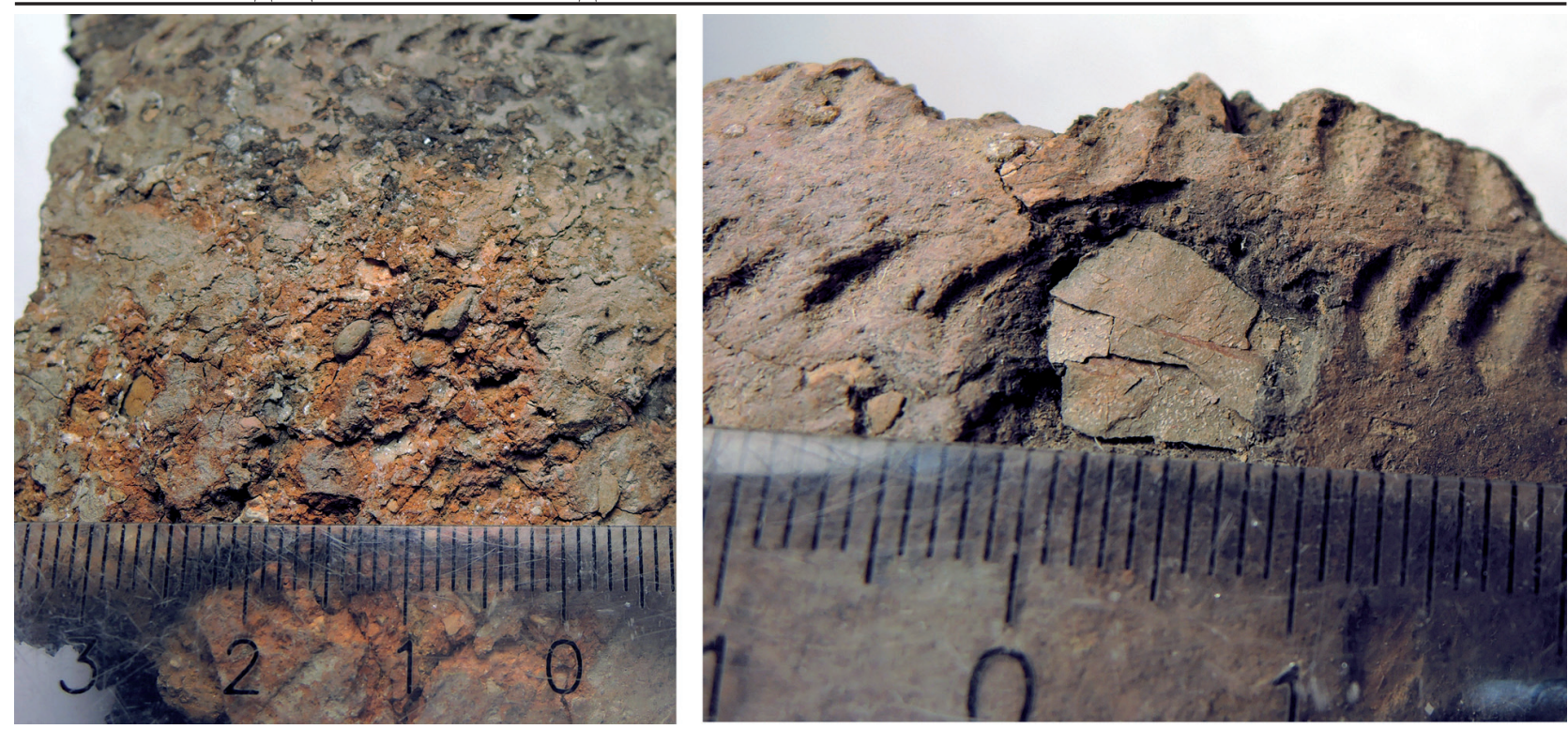

Рисунок 2 - Низкопластичное сырье. Горный Алтай. Афанасьевская культура

афанасьевской культуры, которую, в основном, изготавливали из низко- и среднепластичного сырья, содержавшего крупные частицы. Для всех эпох характерна керамика, изготовленная из среднеожелезненного сырья, сильно и слабоожелезненные глины использовалось редко. Известны единичные случаи применения неожелезненных глин [16]. По материалам всех памятников зафиксировано использование населением нескольких источников исходного сырья.

Формовочные массы. Шамот выявлен в $13 \%$ образцов, а дресва в 17\%. Основное количество сосудов $(70 \%)$ изготовлено без искусственно введенных минеральных примесей. Вероятно, это связано с тем, что использовалось преимущественно низко- и среднепластиное глиноподобное сырье, которое не требовало дополнительного введения минеральных примесей. Шамот применялся афанасьевскими гончарами. Он найден в сосудах нескольких памятников, но основное количество изделий с шамотом происходит из двух могильников. В целом концентрация шамота невелика, что позволяет предположить, что использование его имело преимущественно символический характер. Дресва выявлена в керамике большемысской культуры, эпохи бронзы и раннего железного века. Для раннего железного века добавление дресвы характерно для керамики поселенческих комплексов, а исследуемая посуда из погребений обычно изготовлена из низко- и среднепластичного сырья. Органика, как правило, зафиксирована во всех сосудах. В одних случаях это выжимка навоза, в других количество ее незначительно, что не позволяет определить ее характер (искусственный или естественный). Выделяется серия сосудов неолита и бронзы, при изготовлении которых использована шерсть $[10 ; 11]$.

\section{Предгорный Алтай}

Включает северные и северо-западные предгорья Алтая. Изучена керамика из поселенческих комплексов неолита, бронзы, раннего железного века (большемысской, елунинской культур, ирбинского, крохалевского типов и др.).

Исходное сырье. Сосуды, как правило, изготовлены из пластичного сырья. Из низко- и среднепластичного сырья обнаружено всего несколько изделий. Из естественных примесей обычно фиксируется бурый железняк, различающийся размерами и количеством частиц, мелкий и пылевидный песок в разной концентрации. Известны случаи, когда в сырье керамики из памятников, располагающихся на крупных озерах, находились остатки органики: растительности, костей рыб, обломков раковин.

Для низко- и среднепластичного сырья отмечены различия в составе естественных примесей в зависимости от местонахождения памятника, его удаленности от гор. Например, ирбинские сосуды с поселений на оз. Иткуль, находящихся на периферии предгорной зоны, изготовлены из сырья с примесью мелкого речного песка, концентрация которого иногда достигала 1:1 и 1:2. Такое же сырье изредка использовалось в лесостепном и степном Алтае и доступно и в настоящее время на берегах р. Обь. В северных предгорьях обнаружено четыре сосуда на поселениях раннего железного века, изготовленные из сырья, характерного для горной местности. Не исключено, что эти сосуды из окрестностей с. Точильное были изготовлены не на месте, а принесены из Горного Алтая, т.к. керамика из подобного сырья найдена только в Горном Алтае.

Выявлено использование качественно разного сырья: ожелезненного и неожелезненного, однако последнее встречается как исключение. В частности, несколько сосудов большемысской культуры изготовлены из таких глин.

Формовочные массы. В предгорной зоне значительно чаще добавляли дресву (69\%), а шамот намного реже (12\%). Рецепты, отражающие смешение культурных традиций, т.е. одновременное использование дресвы и шамота, составляют 10\%. Рецептов с одним шамотом зафиксировано мало. В низкопла- 
стичное сырье минеральные примеси не вводили. Органика отмечена, как правило, во всех образцах, однако для керамики эпохи раннего железного века ее количество обычно незначительно: это выжимки навоза или характер ее (искусственная или естественная примесь) определить сложно. Для керамики ранних периодов характерно большое количество органики. Она различается: в крохалевских сосудах - это шерсть, в ирбинских много растительных остатков. Среди ранних комплексов выделяется большемысская посуда, в которой, как правило, нет искусственно введенной органики.

\section{Степной Алтай}

Изучены коллекции поселений из Кулунды, которые датируются, в основном, сер. III тыс. до н.э. и эпохой поздней бронзы, один памятник относится к раннему железному веку.

Исходное сырье. Выявлены две традиции отбора исходного сырья: пластичного и изредка низко- и среднепластичного. Использование второго типа сырья отмечается в керамике середины III тыс. до н.э. и поздней бронзы, изготовленной на гончарном круге. Керамику середины III тыс. до н.э. изготавливали из глин с мелким речным песком, концентрация которого колеблется от $1: 1$ до 1:4-5, различавшихся по количеству и размерам бурого железняка. В некоторых образцах бурый железняк не обнаружен. Сырье, использованное для работы на гончарном круге, в основном, низко- и среднепластичное, но кварцевый песок более мелкий и остроугольный.

В степных районах выявлено использование качественно разного сырья: ожелезненного и неожелезненного. Последнее встречается редко и, в основном, применялось при изготовлении керамики на гончарном круге в эпоху поздней бронзы в качестве второй глины. Из неожелезненного сырья сделана часть шамота. Ожелезненные глины подразделяются на высоко-, средне- и слабоожелезненное. Наиболее часто встречаются сосуды из среднеожелезненных глин.

Формовочные массы. В формовочные массы искусственно вводились шамот (65\%) и дресва (33\%). Смешанные рецепты (шамот + дресва) составляют $21 \%$. Органика зафиксирована в большинстве образцов. Необычные результаты получены для коллекции середины III тыс. до н.э., где в исходное сырье добавляли пух в большой концентрации и, по-видимому, помет птиц. Для керамики эпохи поздней бронзы характерно введение органических растворов. В некоторых случаях определить характер органики не удалось.

\section{Лесостепной Алтай}

Изучена керамика, в основном, из поселенческих комплексов эпохи бронзы - средневековья из районов Верхней Оби.

Исходное сырье. Основная часть сосудов изготовлена из пластичных глин, изредка из низко- и среднепластичнго сырья, в котором концентрация мелкого речного песка колеблется от $1: 1$ до 1:4-5. В качестве естественной примеси встречается бурый железняк, различающийся по размерам и концентрации.

Формовочные массы. Из искусственно введенных минеральных примесей зафиксирован шамот (69\%) и дресва (14\%). Смешанные рецепты составляют 5\%. Органики в ранних комплексах больше, чем в керамике раннего железного века, где она представлена выжимками навоза либо ее характер не определен.

\section{Выводы и перспективы дальнейших}

\section{исследований}

Сравнительный анализ полученных данных показал, что для населения лесостепных, степных и предгорных районов было характерно использование ожелезненных пластичных глин, а для горных - ожелезненного низко- и среднепластичного глиноподобного сырья. Кроме того, в Горном Алтае в раннем железном веке при изготовлении посуды для погребальных ритуалов предпочитали низко- и среднепластичное сырье, а для бытовой посуды - пластичного. Неожелезненное исходное сырье использовали крайне редко во всех районах. Незначительно выделяются керамические комплексы из степей Кулунды, где для изготовления керамики на гончарном круге использовали смесь двух глин ожелезненой и неожелезненной. По материалам всех памятников отмечено использование исходного сырья из разных источников.

Зафиксированы следующие традиции введения минеральных примесей: 1) составление рецептов с одной из минеральных примесей (шамот или дресва); 2) использование смешанных рецептов (дресва + шамот); 3) подготовка масс без минеральных примесей, введенных искусственно. Обращает внимание факт, что во всех изученных районах не выявлено традиции искусственной добавки песка в формовочные массы. Исключение составляет керамика из могильника Локоть-4 (предгорная зона), где в нескольких сосудах зафиксирован песок. Кроме того, крупный остроугольный песок дробили для получения дресвы.

Анализ полученных результатов показал, что традиции в использовании шамота и дресвы, совпадают с ландшафтными особенностями территорий (табл. 1).

Таблица 1 - Результаты корреляции ландшафтных районов и характера минеральных примесей в формовочных массах керамики

\begin{tabular}{|l|c|c|c|c|}
\hline районы & сырье (основная традиция) & шамот & дресва & шамот + дресва \\
\hline горные & низко- и среднепластичное & $\mathbf{1 3 \%}$ & $\mathbf{1 7 \%}$ & - \\
\hline предгорья & пластичное & $\mathbf{1 2 \%}$ & $\mathbf{6 9 \%}$ & $\mathbf{1 0 \%}$ \\
\hline лесостепные & пластичное & $\mathbf{6 9 \%}$ & $\mathbf{1 4 \%}$ & $\mathbf{5 \%}$ \\
\hline степные & пластичное & $\mathbf{6 5 \%}$ & $\mathbf{3 3 \%}$ & $\mathbf{2 1 \%}$ \\
\hline \hline
\end{tabular}

Самарский научный вестник. 2015. №4 (13) 
В лесостепных районах наиболее высок показатель сосудов с шамотом (69\%) и наиболее низкий с дресвой (14\%), смешанные рецепты составляют 5\%. В степных районах сосудов с шамотом практически столько же, как и в лесостепном (65\%), но больше изделий с дресвой (33\%) и со смешанными рецептами (21\%). Видимо, на традиции использования минеральных примесей населения степных районов оказало влияние население Казахстана, для которого было более характерно использование дресвы. Культурные контакты населения этих регионов зафиксированы и по другим источникам [17].

В предгорных районах сосуды с дресвой более многочисленны, чем в горах (69\% и 17\%), а число изделий с шамотом близко к показателю по горным областям (12 и 13\%) Однако, в керамике предгорных районов шамот обнаружен в большинстве случаев в смешанных рецептах (10\%). Сосуды с одним шамотом составляют около $2 \%$. Кроме того, изделия с шамотом найдены на памятниках периферийных районов, удаленных от выходов камня. Керамика этих поселений имеет значительно больший процент смешанных рецептов. На показатели с шамотом в предгорном Алтае оказали влияние результаты исследований афанасьевской керамики с поселения Подсинюшки, которые увеличили процент сосудов с шамотом в предгорной зоне.

В целом, в Горном Алтае зафиксировано наименьшее использование искусственно введенных минеральных примесей, среди которых незначительно преобладает традиция применения дресвы (шамот 12\%, дресва 17\%). Шамот зафиксирован в афанасьевской керамике. Учитывая, что для других керамических комплексов разных культур из горных и предгорных районов использование шамота не характерно, а также, что отмечается угасание традиции использования шамота афанасьевскими гончарами, можно предположить, что эти навыки были принесены на территорию Горного Алтая афанасьевскими мастерами [9]. Данное предположение подкрепляется гипотезой о пришлом характере афанасьевского населения в Горном Алтае, а также итогами других исследований, в т.ч. палеоантропологических [16; $18 ; 129 ; 20$ и др.].

Подводя итог, отметим, что в районах, где доступны выходы камня, основной традицией было использование дресвы, а шамот добавляли там, где выходов камня не было. Нельзя не обратить внимание на то, что в периферийных районах предгорий, где до выходов камня не менее 80 км, преобладают изделия с дресвой или смешанные рецепты. Необходимо отметить, что для поселенческих керамических комплексов эпохи бронзы - раннего железного века Горного Алтая было более характерно применение пластичных глин, в которые вводили дробленый камень, чем использование низко- и среднепластичного сырья, не требующего дополнительного введения минеральных примесей.

Продолжение исследования керамики в рамках историко-культурного подхода позволит выяснить, с чем связаны различия традиций изготовления керамики для использования в быту и в ритуальных целях в Горном Алтае. Важно также уточнить: является ли это наблюдение закономерностью, изготавливали ли эти сосуды гончары одних и тех же поселков, или же отмеченные различия вызваны культурными, этнографическими и хронологическими различиями? Кроме того, увеличение источниковой базы позволит уточнить количественные данные по отмеченным закономерностям использования минеральных примесей в зависимости от ландшафтных характеристик. Это даст возможность не только отмечать факт смешения традиций, но и определять направление связей древнего населения

\section{СПИСОК ЛИТЕРАТУРЫ:}

1. Бобринский А.А. Гончарство Восточной Европы. Источники и методы изучения. М.: Наука, 1978. $272 \mathrm{c}$.

2. Бобринский А.А. Гончарная технология как источник информации о процессах смешения древнего населения // Тезисы докладов советской делегации на IV международном конгрессе славянской археологии. София, сентябрь, 1980. М., 1980. С. 57-59.

3. Бобринский А.А. Отражение эволюционных и миграционных процессов в особенностях древней гончарной технологии // Палеодемография и миграционные процессы в Западной Сибири в древности и средневековье. Барнаул, 1994. С. 14-16.

4. Бобринский А.А. Гончарная технология как объект историко-культурного изучения // Актуальные проблемы изучения древнего гончарства (коллективная монография). Самара: Изд-во СамГПУ, 1999. С. 5-109.

5. Цетлин Ю.Б. Древняя керамика. Теория и методы историко-культурного подхода. М., 2012. 384 с.

6. Степанова Н.Ф. Керамика большемысской культуры поселения Малый Дуган // Сохранение и изучение культурного наследия Алтайского края. Барнаул, 1997. С. 113-116.

7. Степанова Н.Ф. Предварительные итоги исследования формовочных масс афанасьевских сосудов из погребальных комплексов Горного Алтая // Проблемы археологии, этнографии, антропологии Сибири и сопредельных территорий. Т. X, ч.II. Материалы Годовой сессии Института археологии и этнографии СО РАН 2004 г. Новосибирск, 2004. С. 236-240.

8. Степанова Н.Ф. О традициях изготовления глиняной посуды в эпоху бронзы в Горном Алтае (исходное сырье и формовочные массы) // Производственные центры: источники, «дороги», ареал распространения. СПб., 2006. С. 159-163.

9. Степанова Н.Ф. К вопросу об адаптации населения афанасьевской культуры Горного Алтая (по материалам керамических комплексов) // Культурноэкологические области: взаимодействие традиций и культурогенез. СПб, 2007. С. 95-104.

10. Степанова Н.Ф. Предварительные итоги исследований исходного сырья и формовочных масс керамики неолита-бронзы Горного Алтая и его пред- 
горий // Изучение историко-культурного наследия народов Южной Сибири. Вып. 7. Горно-Алтайск. 2008. С. 23-31.

11. Степанова Н.Ф. Особенности исходного сырья и формовочных масс керамики эпохи неолита и бронзы Горного Алтая и его северных предгорий // Древнее гончарство: итоги и перспективы изучения. М., 2010. С. 117-125.

12. Кирюшин Ю.Ф. Энеолит и ранняя бронза юга Западной Сибири. Барнаул, 2002. 294 с.

13. Вадецкая Э.Б., Поляков А.В., Степанова Н.Ф. Свод памятников Афанасьевской культуры. Барнаул, 2014. 380 c.

14. Кирюшин Ю.Ф., Абдулганеев М.Т., Степанова Н.Ф. Предварительные итоги исследований исходного сырья и формовочных масс керамики большемысской культуры // Проблемы археологии, этнографии, антропологии Сибири и сопредельных территорий. Т. XII, ч.I. Новосибирск, 2006. С. 341-344.

15. Кунгуров А.Л. Каменная индустрия поселения Узнезя-1 // Погребальные и поселенческие комплексы эпохи бронзы Горного Алтая. Барнаул, 2006. С. 84-119.
16. Степанова Н.Ф. Результаты исследований формовочных масс сосудов из афанасьевского могильника Сальдяр-1 // Ларин О.В. Афанасьевская культура Горного Алтая: могильник Сальдяр-1. Барнаул, 2005. C. 155-159.

17. Бейсенов А.З., Ломан В.Г. Древние поселения Центрального Казахстана. Алматы, 2009. 264 с.

18. Тур С.С., Рыкун М.П. Палеоэкология населения афанасьевской культуры Горного Алтая // Погожева А.П., Рыкун М.П., Степанова Н.Ф., Тур С.С. Эпоха энеолита и бронзы Горного Алтая. Ч. 1. 2006. С. 60-114.

19. Чикишева Т.А. Особенности динамики антропологического состава населения горного Алтая в древности от эпохи неолита до начала нашей эры // Сибирь в панораме тысячелетий. Т. 1. Новосибирск, 1998.

20. Чикишева Т.А. Антропологический аспект взаимодействия населения афанасьевской культуры с автохтонным населением на территории Горного Алтая // Афанасьевский сборник. Барнаул, 2010. C. 259-273.

\section{CULTURAL TRADITIONS IN SELECTION OF FEEDSTOCK AND MINERAL ADMIXTURES IN CERAMICS PRODUCTION (ON THE GROUND OF MATERIALS FROM THE MOUNTAINOUS, FOOTHILL, STEPPE AND FOREST-STEPPE AREAS OF ALTAI)}

(C) 2015

N.F. Stepanova, candidate historical sciences

Institute of archeology and ethnography of the Siberian Branch of the Russian Academy of Sciences, Barnaul laboratory of archeology and ethnography of Southern Siberia, Barnaul (Russia)

Abstract. The article is devoted to generalization of results of the technical and technological analysis of the ceramics from settlement and funeral complexes of Altai dated from the Neolithic era to the Middle Ages. Cultural traditions in selection of feedstock and preparation of moulding masses, depending on landscape characteristics of territories where monuments are found, are analyzed in the article. It is established that for steppe, forest-steppe and foothill areas the use of ferruginous (iron-rich) flexible clays is characteristic, and as for mountain areas, the use of low ferruginous and medium ferruginous claylike material is typical. Differences of cultural traditions and differences in use of mineral admixtures, coinciding with landscape characteristics of areas where monuments are located, are revealed. The addition of chamotte is typical for forest-steppe and steppe Altai (69\% and 65\%), and the addition of gruss - for foothill Altai (69\%). In Mountain Altai production of ceramics without artificially entered mineral admixtures was the main tradition: chamotte and gruss are recorded in $13 \%$ and $17 \%$ of vessels, respectively, that in total makes $30 \%$. The mixed recipes (gruss + chamotte) prevail in peripheral regions of the foothill zone. Such observations allowed drawing a conclusion that in areas with stone outcrop gruss had been added to moulding masses, and chamotte had been added in places with no stone outcrop. The mixed recipes (gruss + chamotte) reflect not only the merging of cultural traditions, but also the mixing of population from the areas with different landscape characteristics.

Keywords: ceramics; feedstock; mineral admixtures; chamotte; moulding masses; cultural traditions; landscape; New Stone Age; Afanasyevsky culture; Bolshemys culture; eras of bronze and early Iron Age; Altai. 